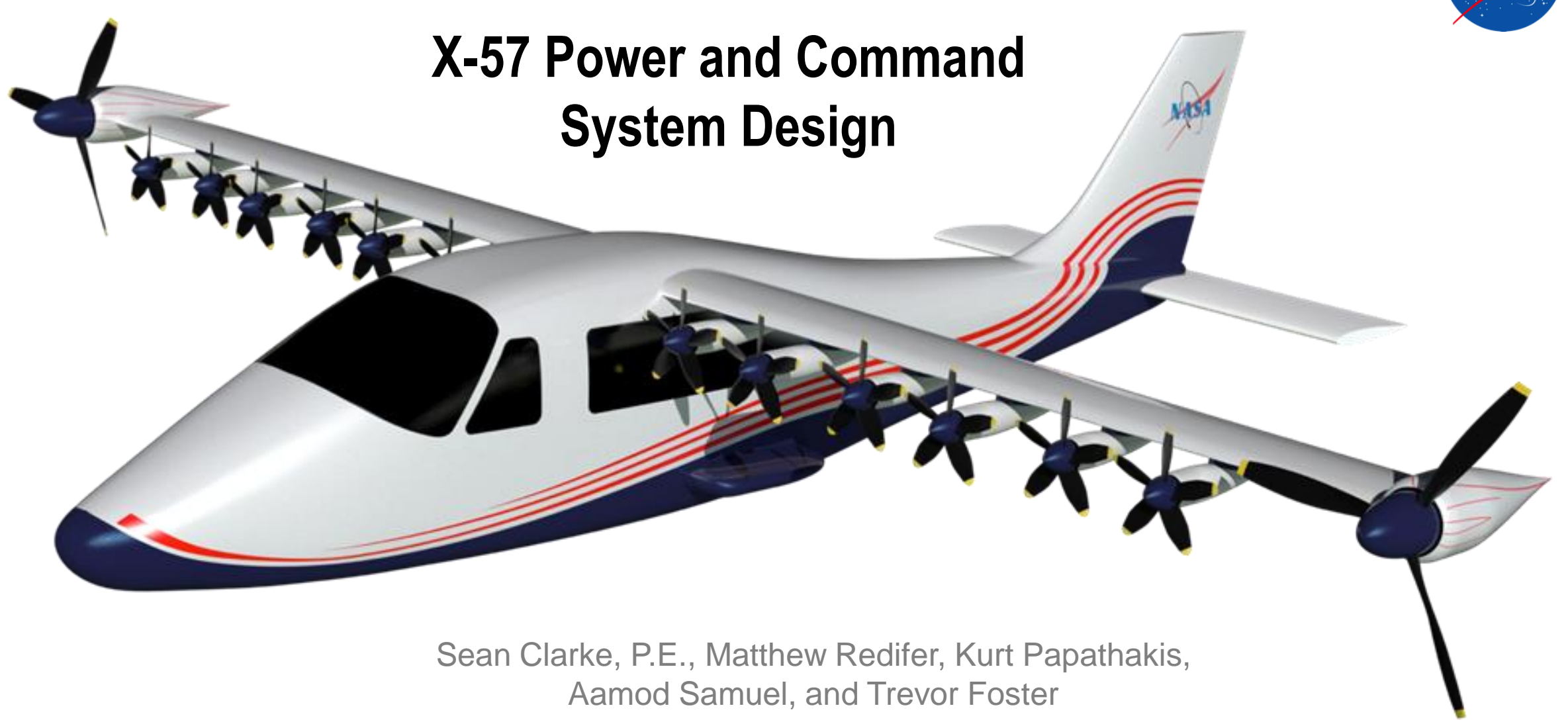
Aamod Samuel, and Trevor Foster 


\section{X-57 Power And Command System Overview}

- Avionics Power System

, $13.8 \mathrm{~V}$, powers flight deck, traction system computers, instrumentation system

- Traction Power System

, $461 \mathrm{~V}, 18650$ battery cells, redundant distribution buses

- Command System

> CAN Bus, digital throttle link to torque controllers, fiber optic links

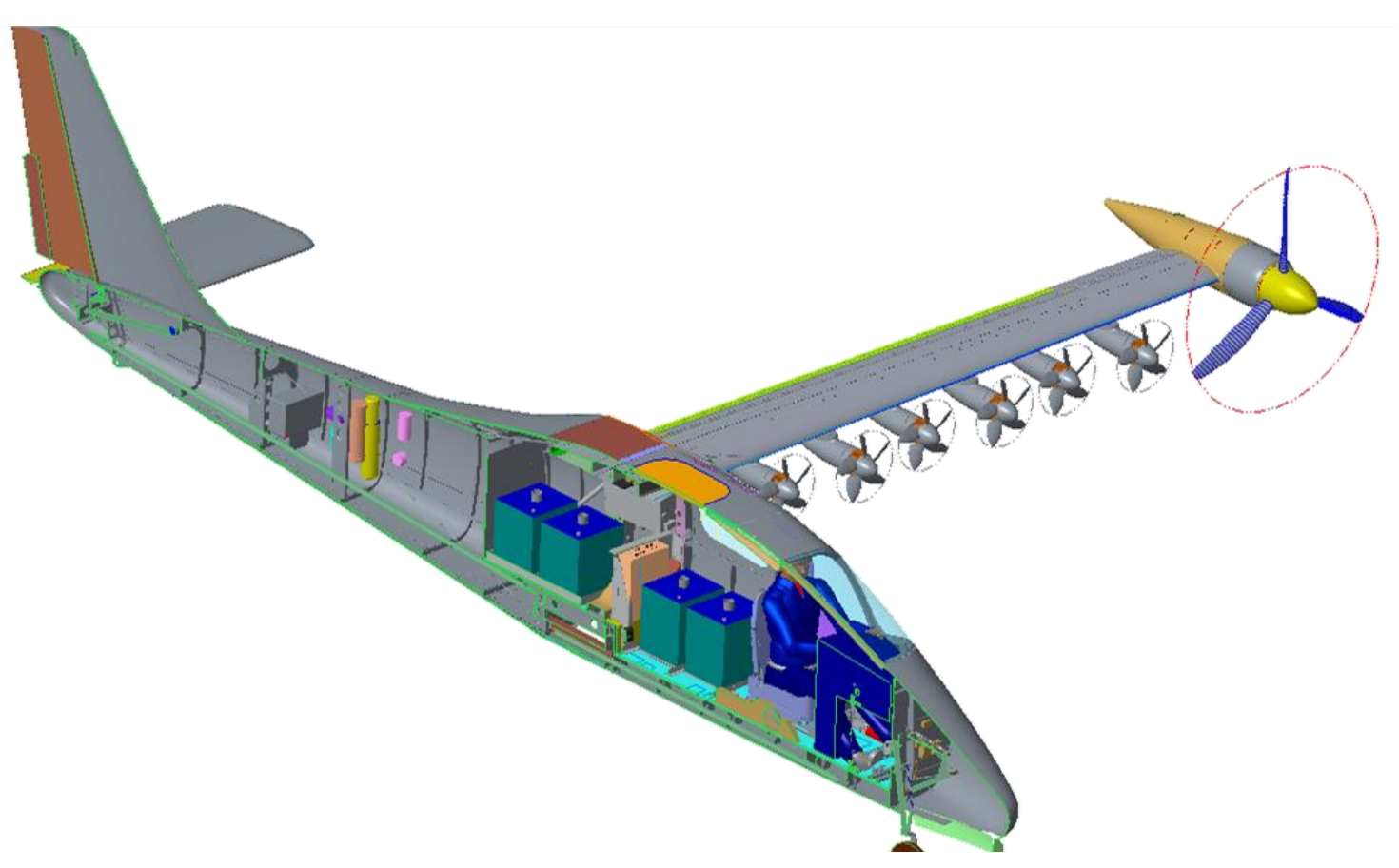




\section{Avionics Power System}

- Maintains/extends original discrete buses to enable load shedding

- Powered by DC/DC converters in the redundant HV battery system

- Essential Bus backed up by certified lead-acid battery

- New redundant buses routed throughout wing for remote command / instrumentation components

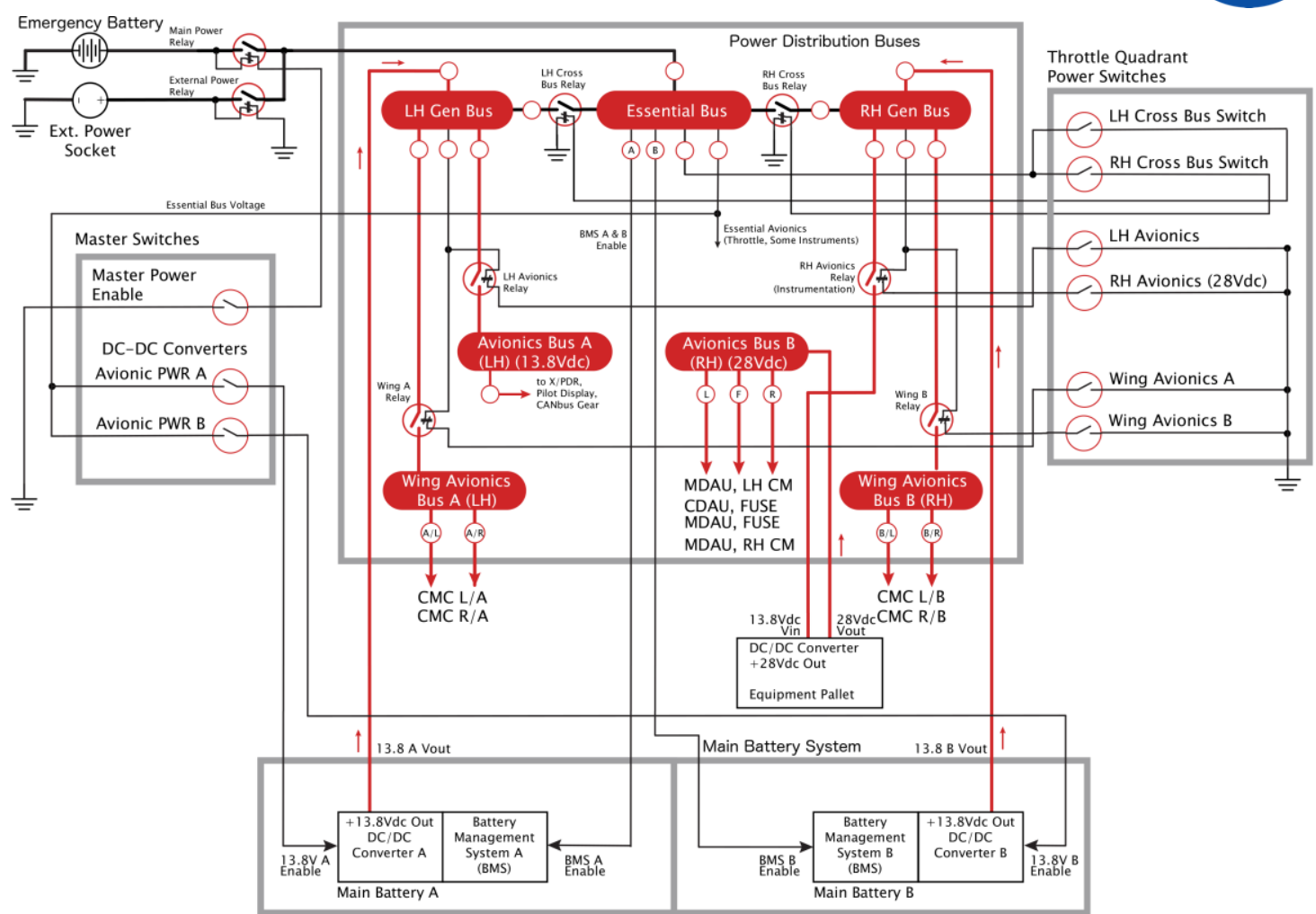

The X-57 avionics power system interconnect 


\section{Traction Power System}

- High voltage DC distribution system, nominally $460 \mathrm{~V}$.

- Redundant batteries, charges to $530 \mathrm{~V}$

- Redundancy includes battery, contactors, distribution bus, torque controller, motor

- Two 20p128s batteries using 18650 cells with custom safety features

- Novel "Flat Cable"

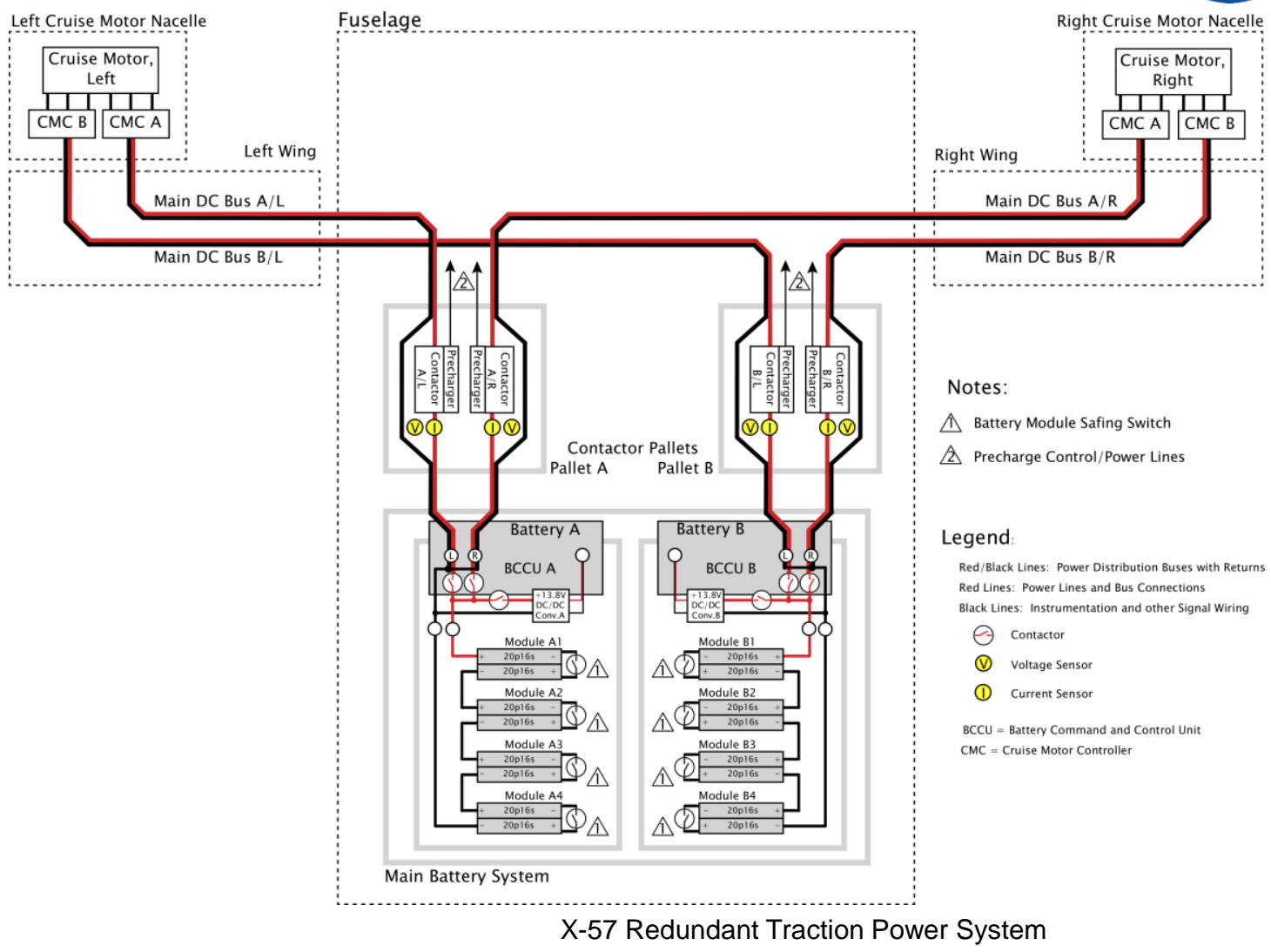




\section{Traction Distribution Bus: "Flat Cable"}

- Flat cable is expected to reduce $D C$ distribution bus inductance and farfield radiated emissions

- Improved bend radius required for routing to the distributed motors

- Form factor complies with low-profile X-57 wing while maintaining sufficient ampacity

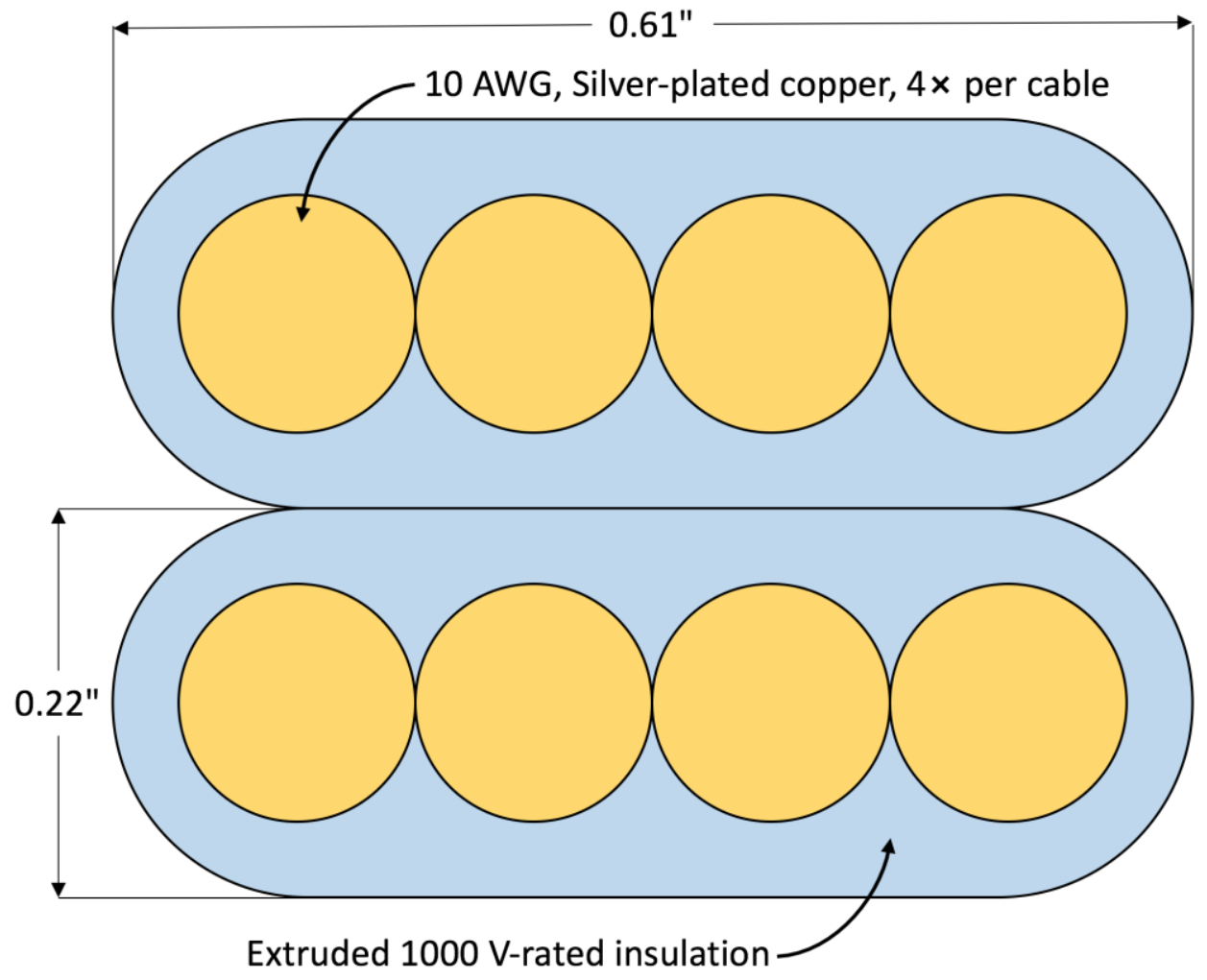

X-57 Traction Cable dimensions 


\section{Traction Distribution Bus: "Flat Cable"}

- Flat cable is expected to reduce $D C$ distribution bus inductance and farfield radiated emissions

- Improved bend radius required for routing to the distributed motors

- Form factor complies with low-profile X-57 wing while maintaining sufficient ampacity

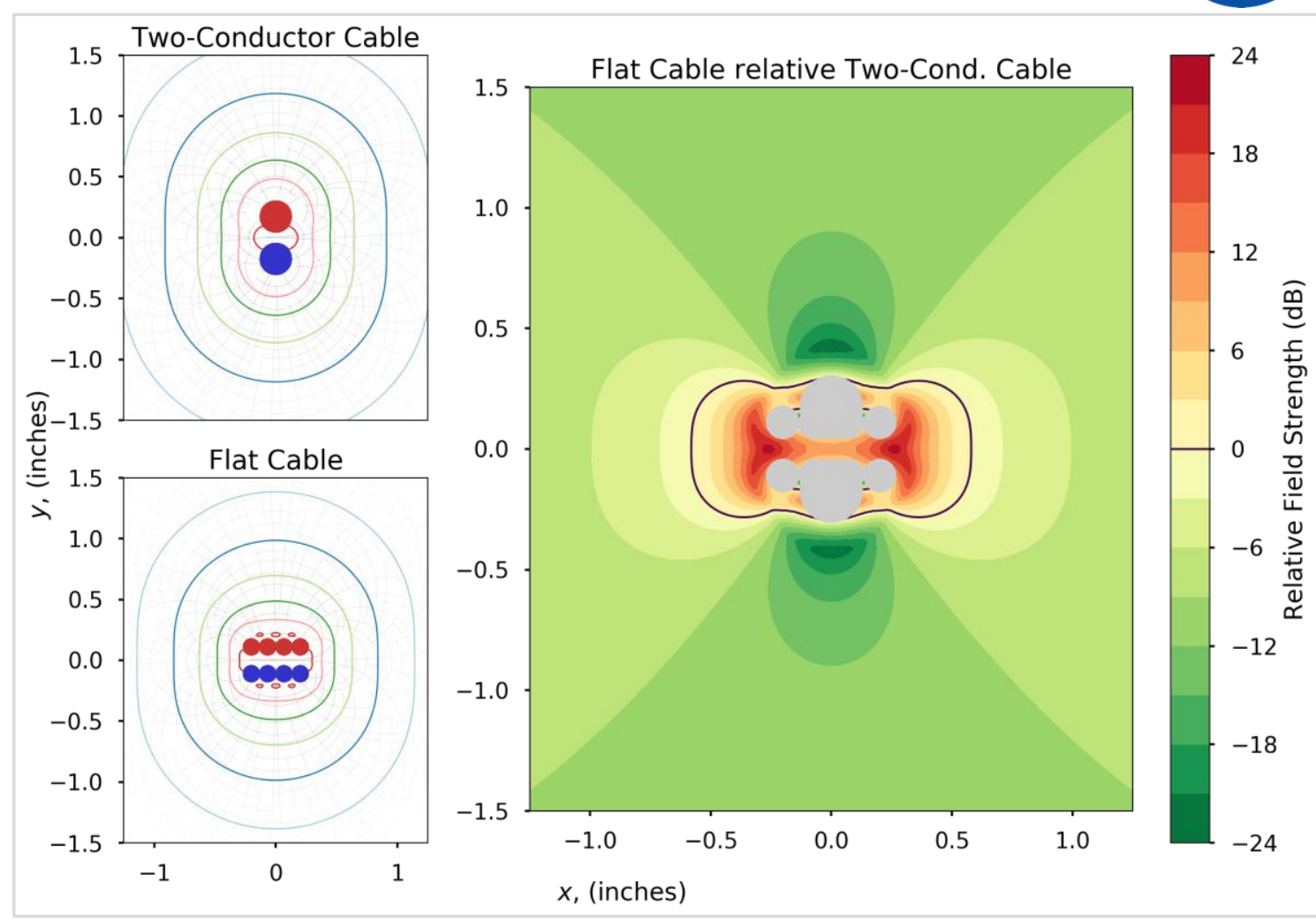

Near-field electric and magnetic field strength comparison between traditional two-conductor cable and the X-57 "flat cable" configuration 


\section{Traction Distribution Bus: "Flat Cable"}

- Flat cable is expected to reduce $D C$ distribution bus inductance and farfield radiated emissions

- Improved bend radius required for routing to the distributed motors

- Form factor complies with low-profile X-57 wing while maintaining sufficient ampacity

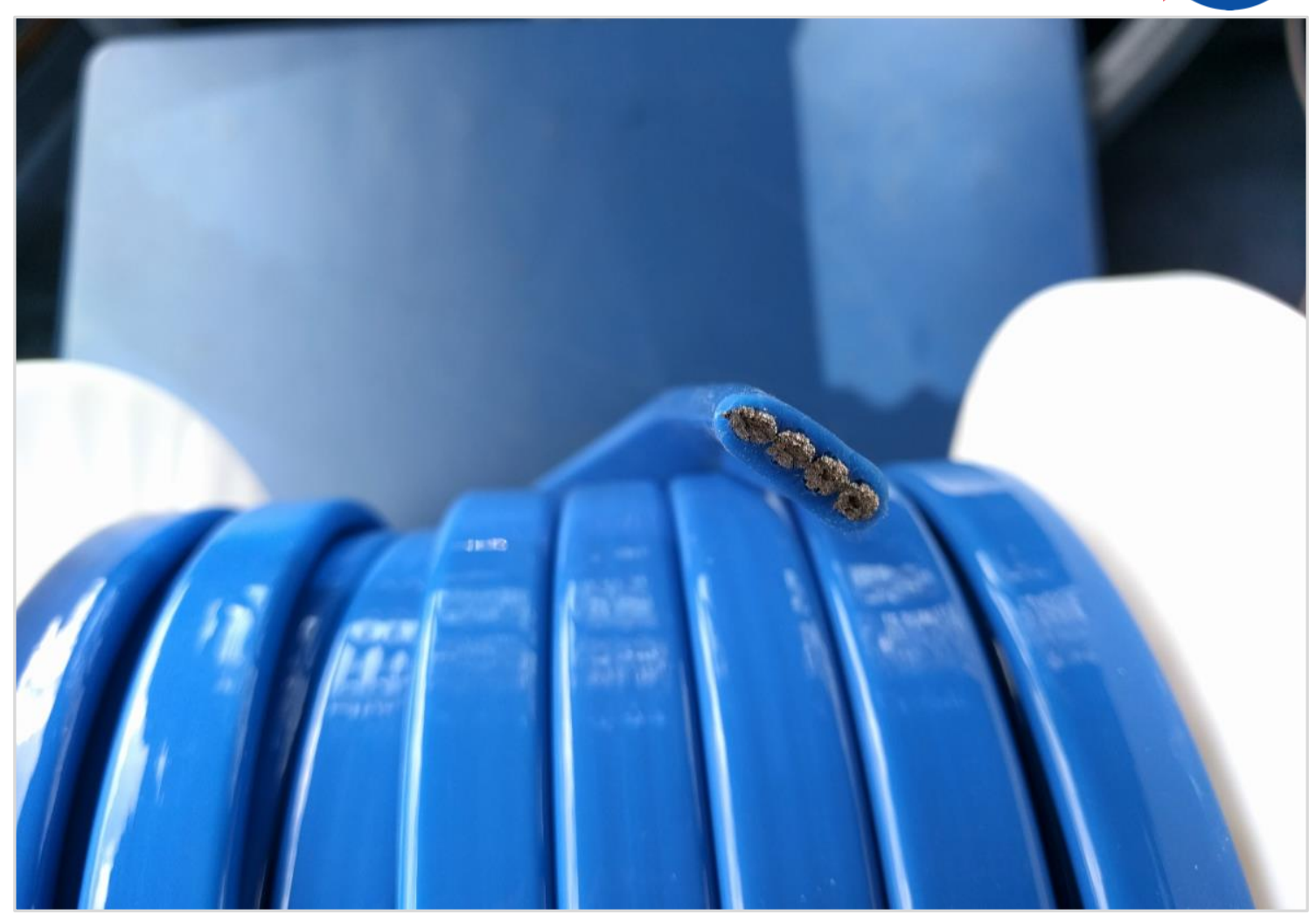




\section{Battery System}

JSC Test Unit With Interstitial Barrier and Heat Spreader (Design Template)

- $461 \mathrm{~V}$ nominal, 47 kWh capacity

- 790 lbs. (8 Modules, 95 lbs. each)

- 2 packs supports redundant X-57 traction system

- Battery destructive testing conducted Dec 2016.

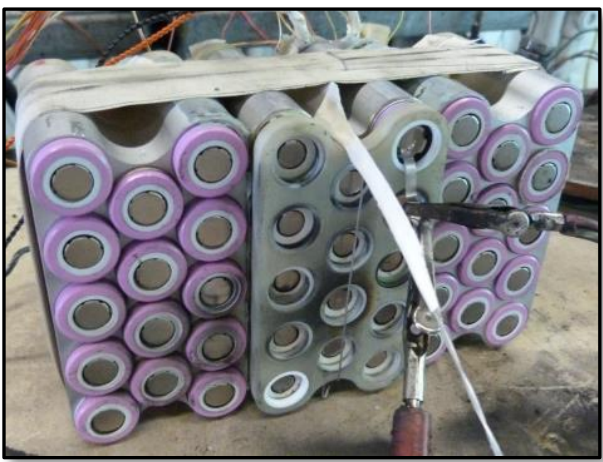

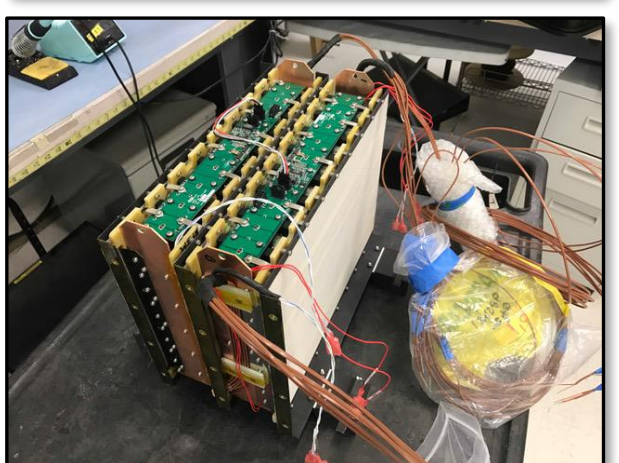

X-57 Thermal Runaway Unit (2 Trays; $1 / 2$ Module)
X-57 Battery Module (1/4 Pack) before Short Circuit Test
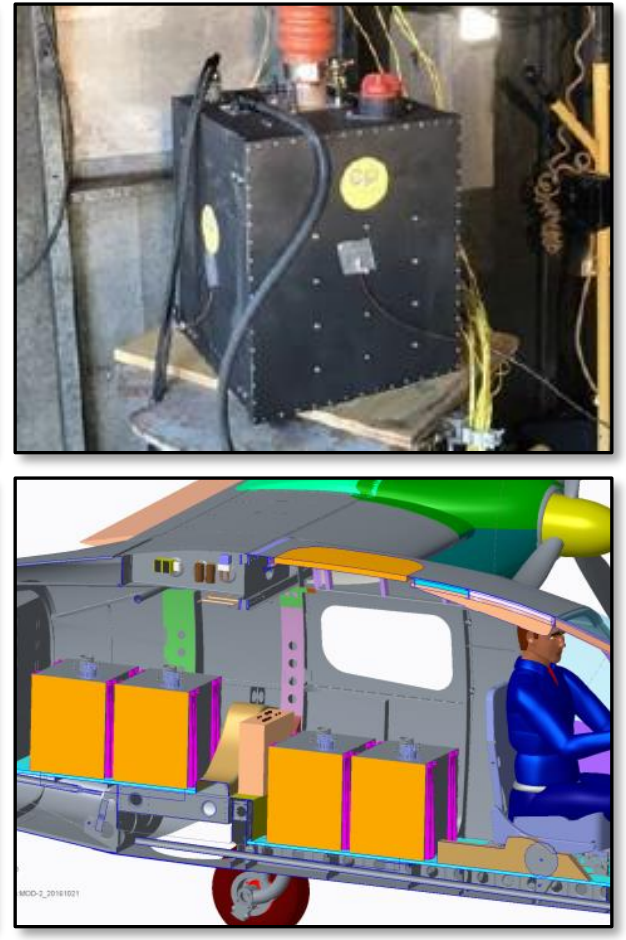

One Battery Pack (4 Module, 1/2 Ship Set) 


\section{Cruise Motor Torque Controllers (Inverters)}

Heatsink Uses Cruise Motor Exhaust To Cool Inverter Gates

- Prototype Running at $200 \%$ of rated power

- Software initial release in preliminary verification and validation testing

- Environmental screening (shake and bake) of prototype unit in progress at AFRC

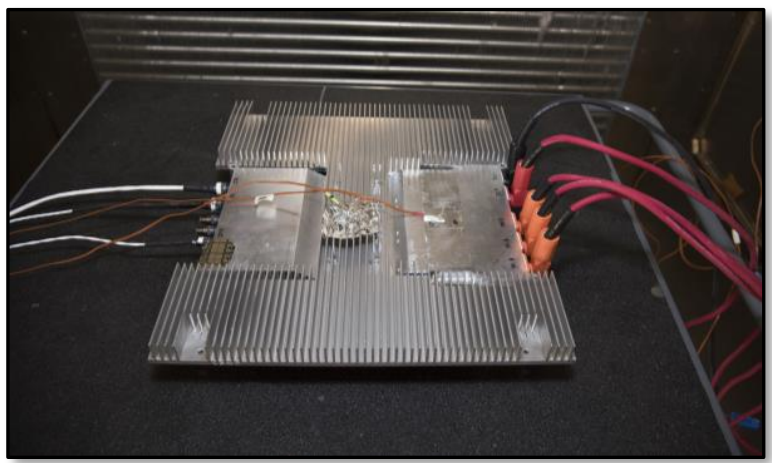

CMC Environmental Testing at NASA

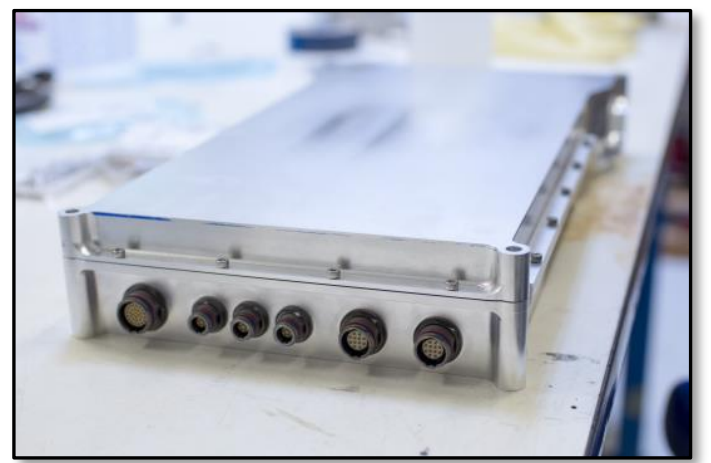

Communication, Power and Sensor Interface (Output) Interface to the Inverter 


\section{Cruise Motor}

- Flight motor fabrication in progress, first unit delivery in April

- Out-runner design further optimized for X-57 based on prototype performance (demonstrated large margins)
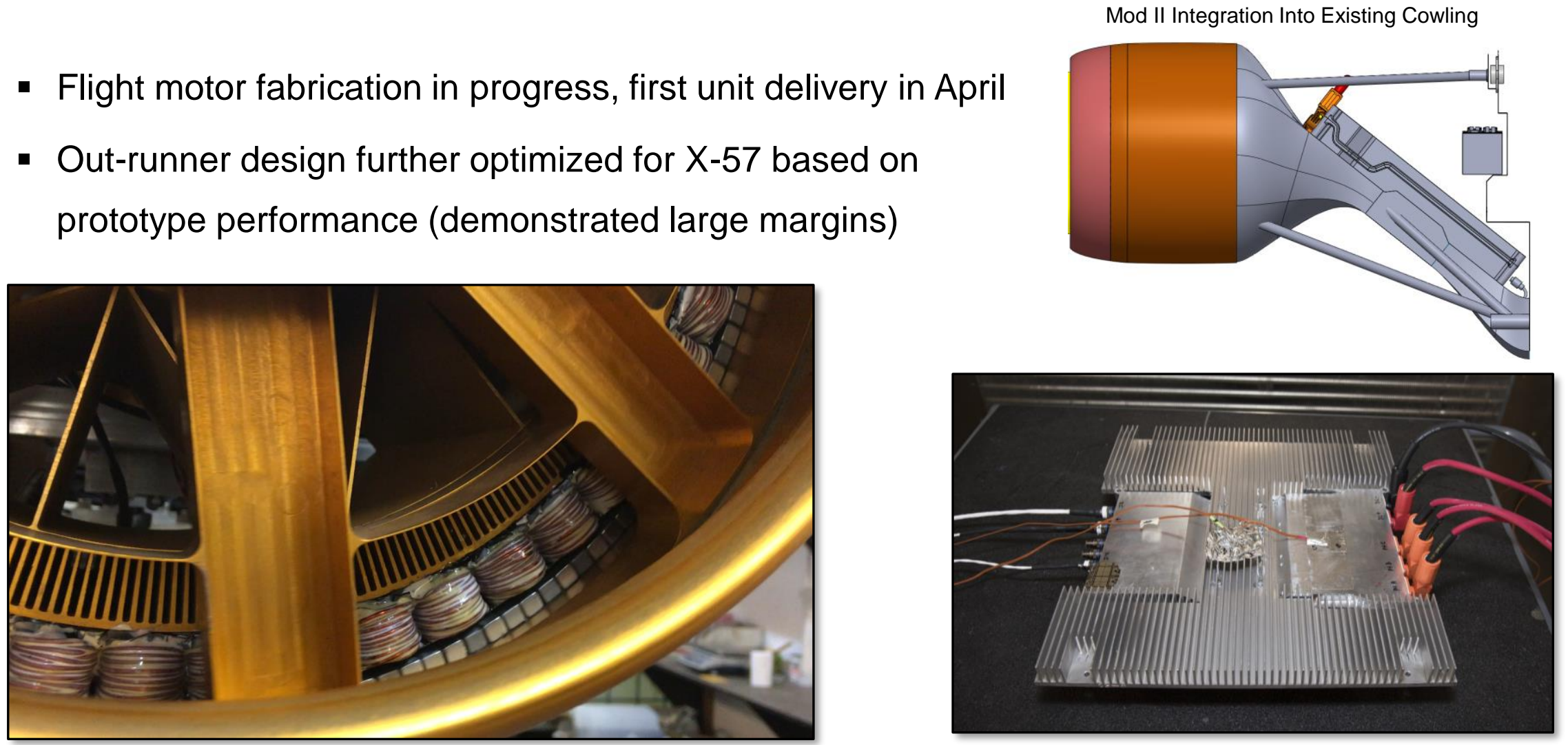

Prototype Cruise Motor (Design Iteration J, Flight Units Will Be Rev K) 


\section{Cruise Motor Development - Rev J Prototype Testing}

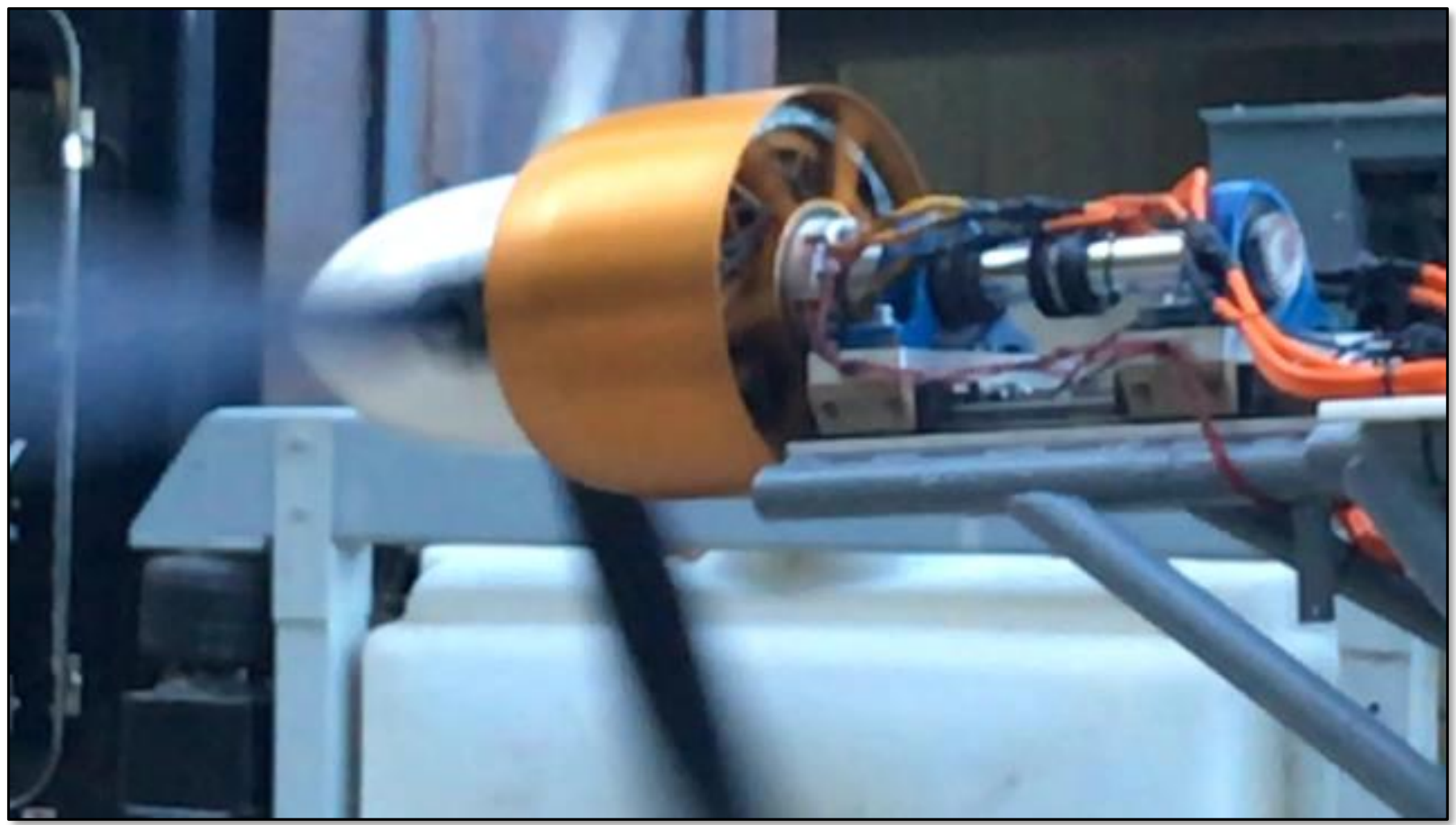




\section{Command System}

- 1000 kbaud CAN Bus divided into independent segments by fiber links

- Redundant digital throttle encoder, COTS displays / sensors, status computer

- Safety critical software development for CMC, BMS reduces criticality of rest of the system

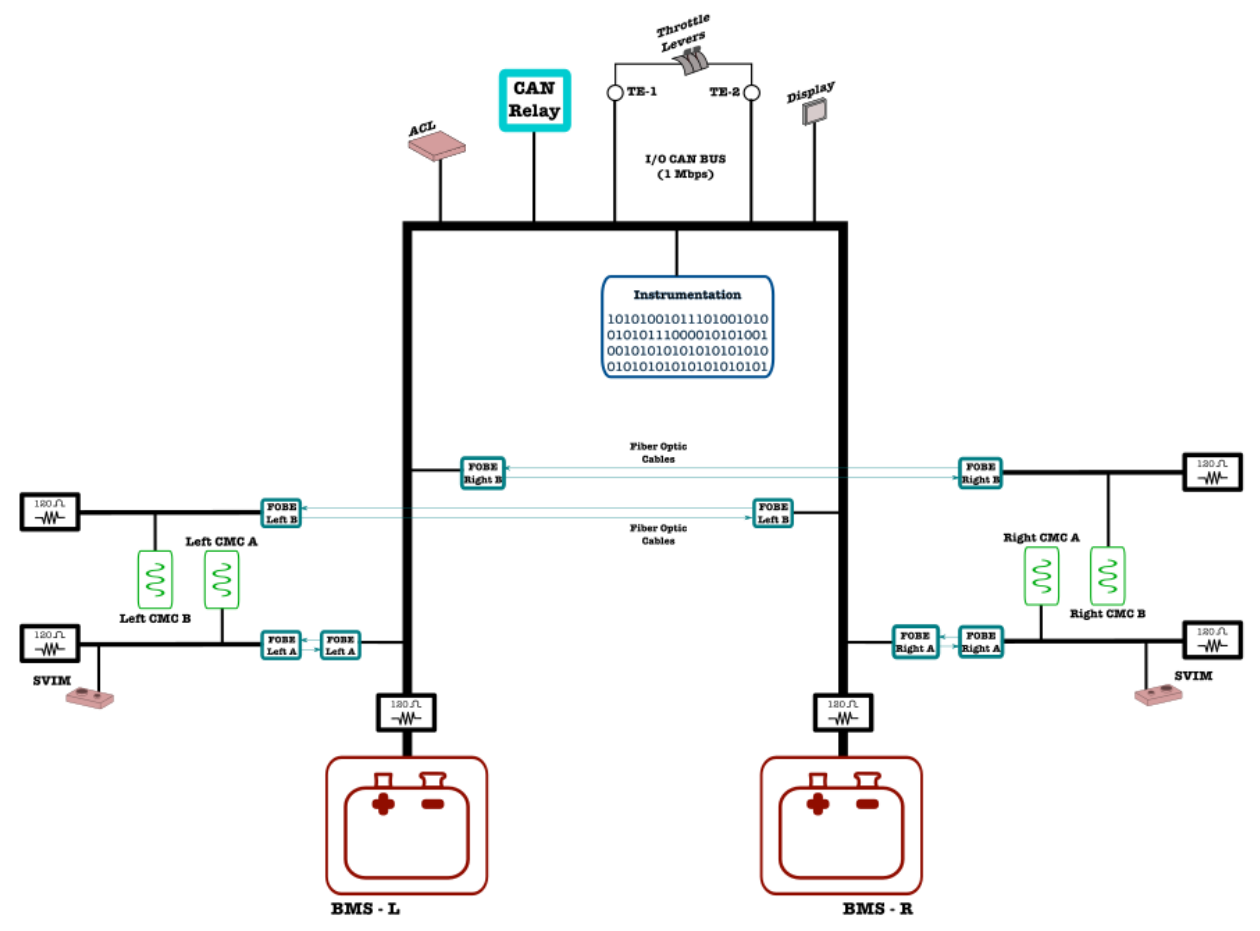

The X-57 command system network diagram 


\section{Command System}

- 1000 kbaud CAN Bus divided into independent segments by fiber links

- Redundant digital throttle encoder, COTS displays / sensors, status computer

- Safety critical software development for CMC, BMS reduces criticality of rest of the system

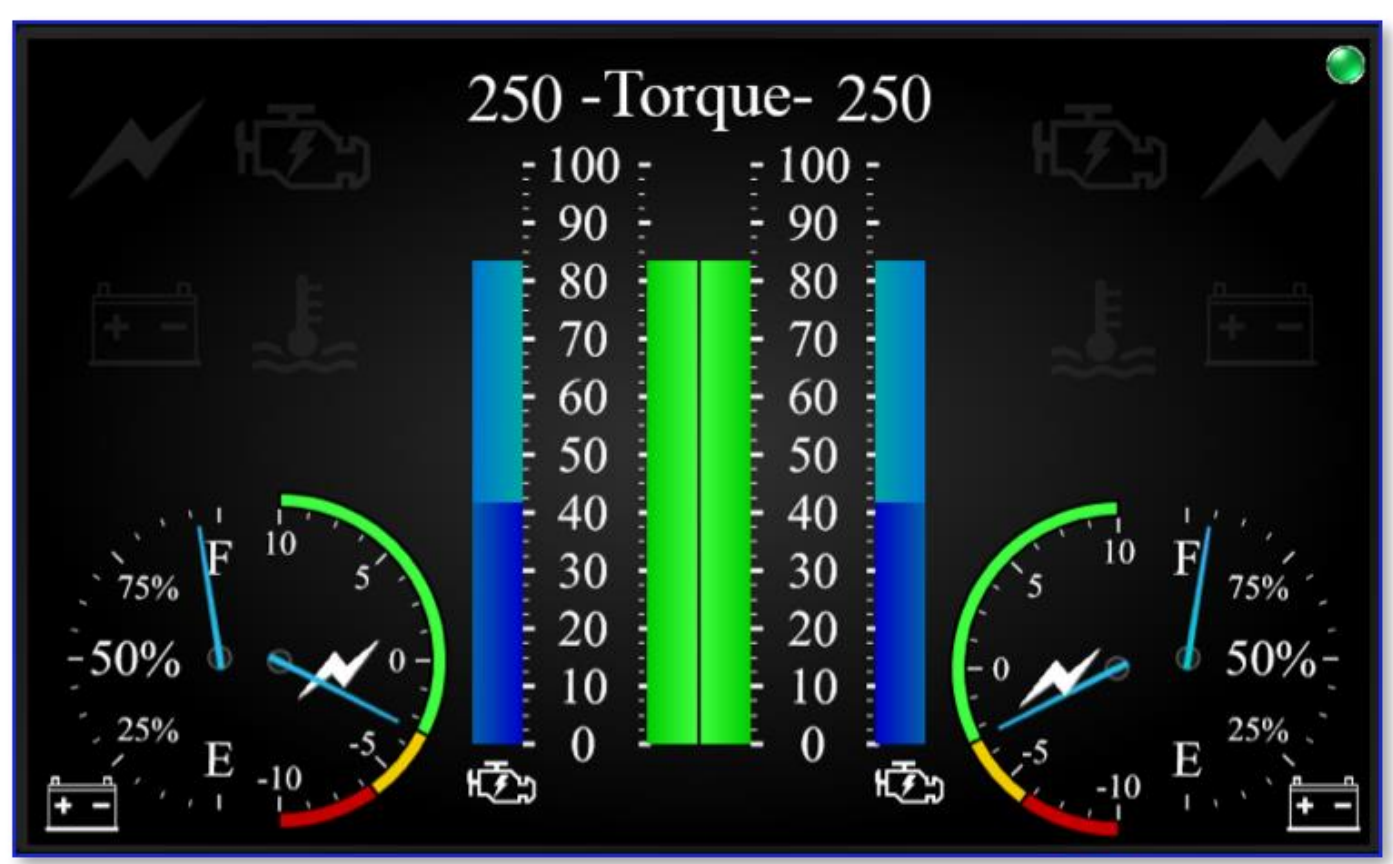

The X-57 cockpit display reflects the duality of the X-57 system design. Indicators include State of Charge, discharge rate, and throttle position. 


\section{Command System}

- 1000 kbaud CAN Bus divided into independent segments by fiber links

- Redundant digital throttle encoder, COTS displays / sensors, status computer

- Safety critical software development for CMC, BMS reduces criticality of rest of the system

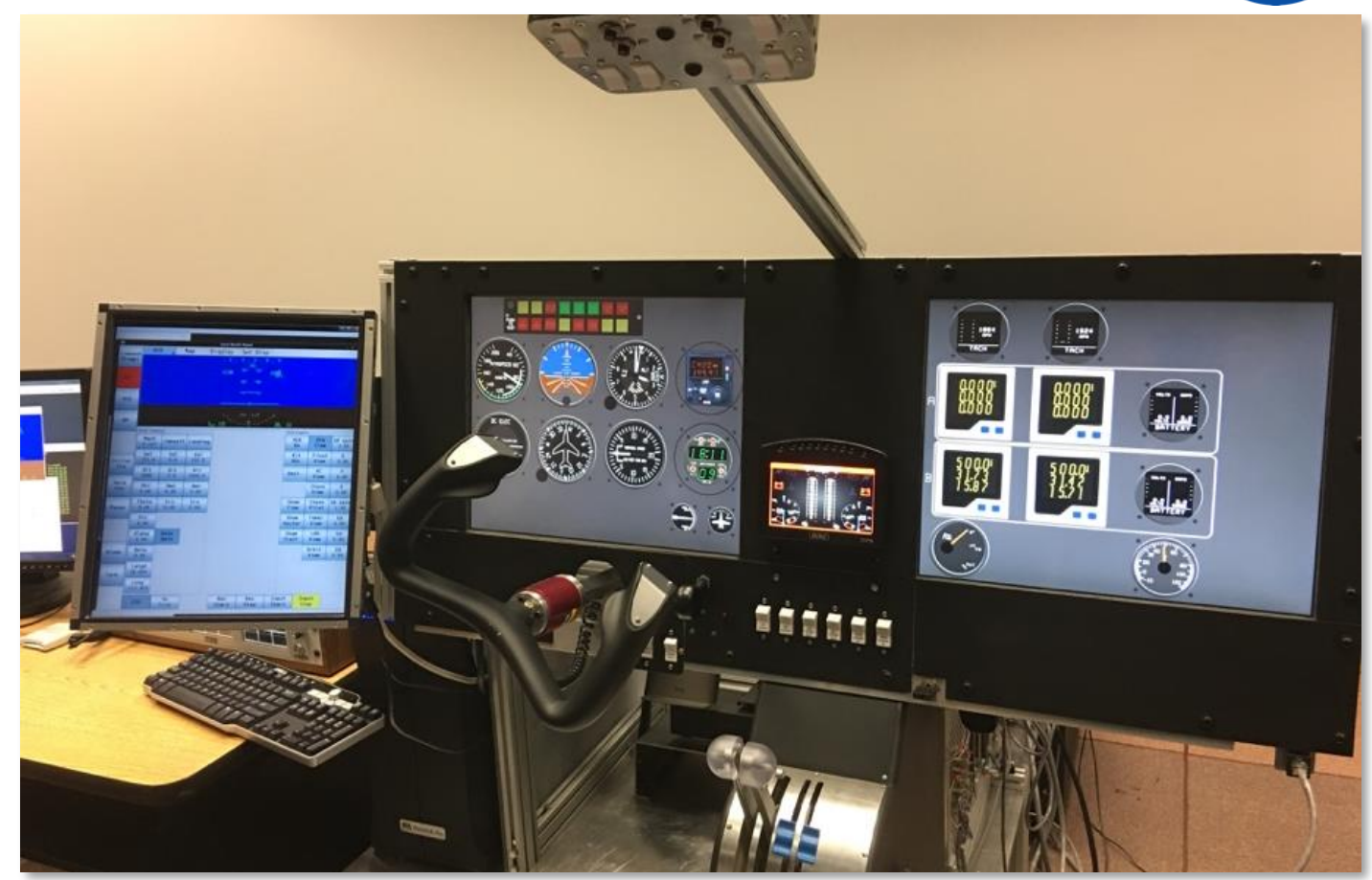

The X-57 cockpit display reflects the duality of the X-57 system design. Indicators include State of Charge, discharge rate, and throttle position. 
- Developing an extensive Failure Modes and Effects Analysis (FMEA) which covers traction, avionics, command, and instrumentation systems

- Each failure mode is analyzed for criticality and likelihood which determines which FMET tests are required

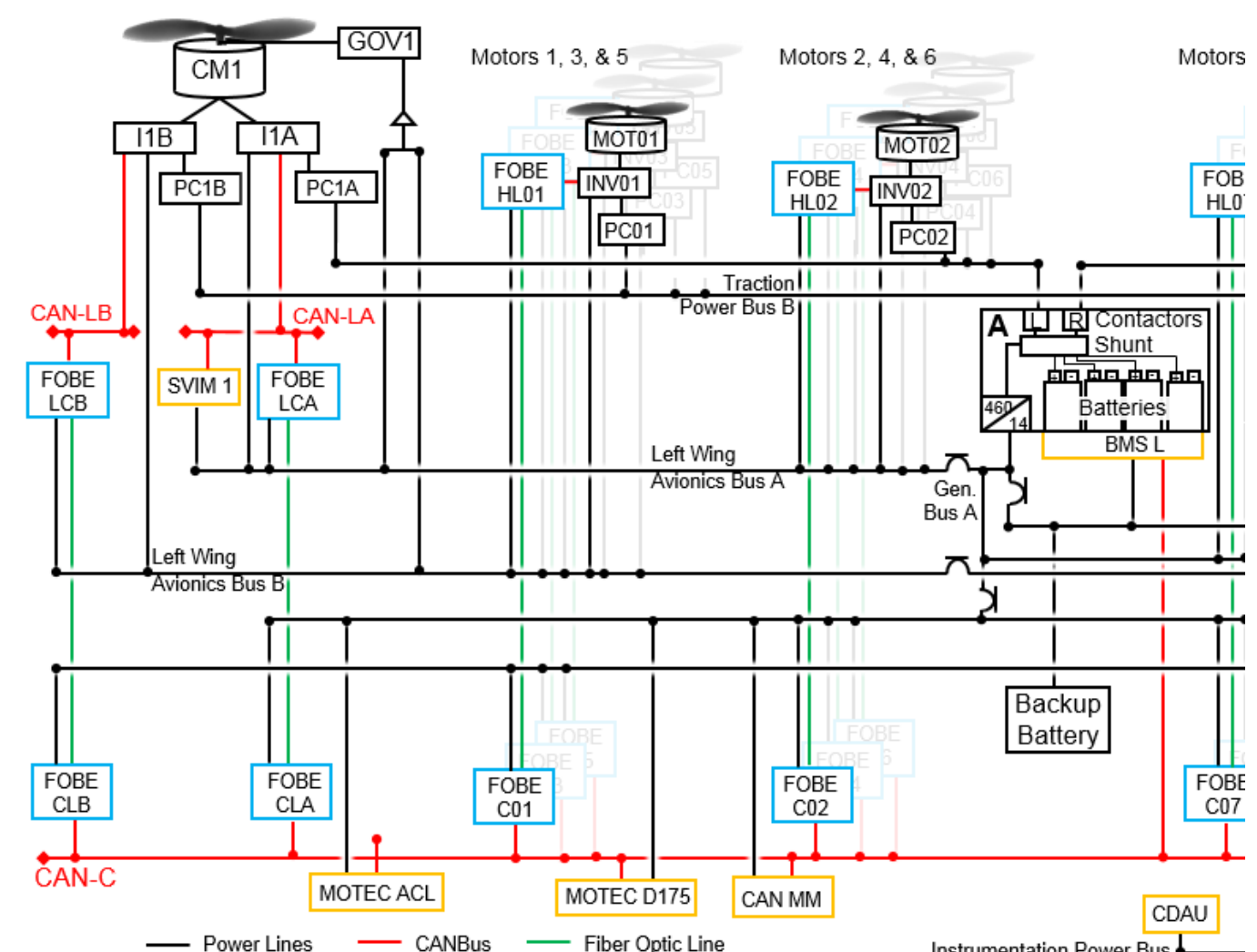

- Power Lines - CANBus - Fiber Optic Line 


\section{Risk Mitigation}

- Developing an extensive Failure Modes and Effects Analysis (FMEA) which covers traction, avionics, command, and instrumentation systems

- Each failure mode is analyzed for criticality and likelihood which determines which FMET tests are required

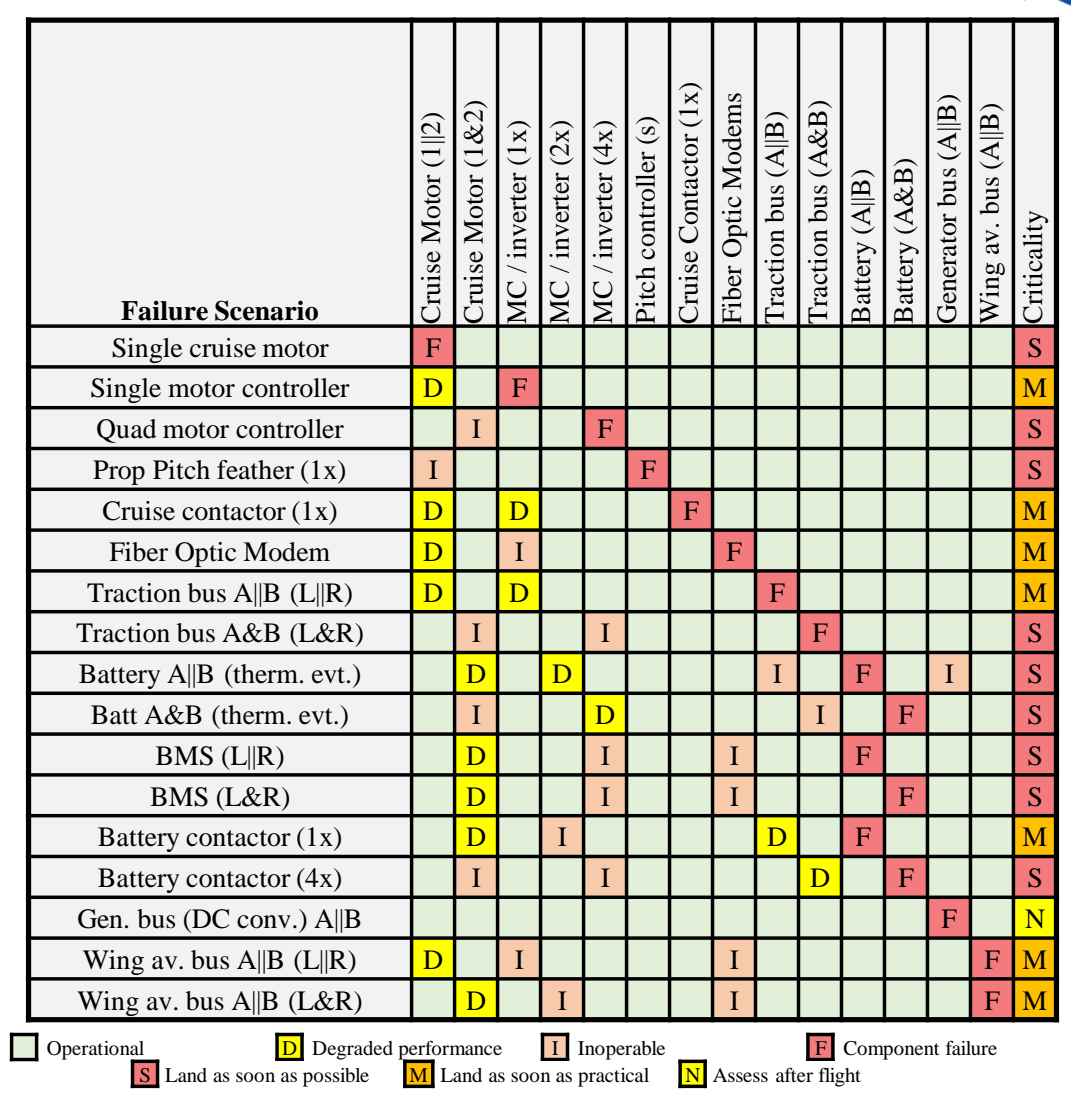

X-57 Mod II and Mod III Failure Scenario Matrix 


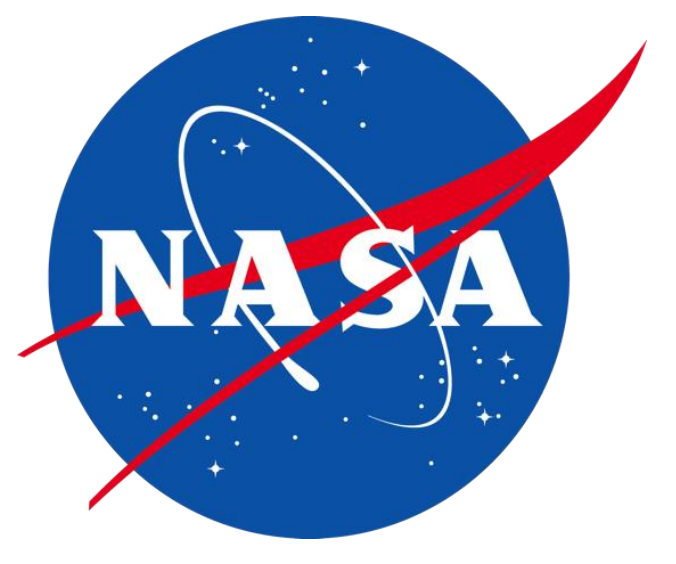




\section{Project Approach}

Mod 1
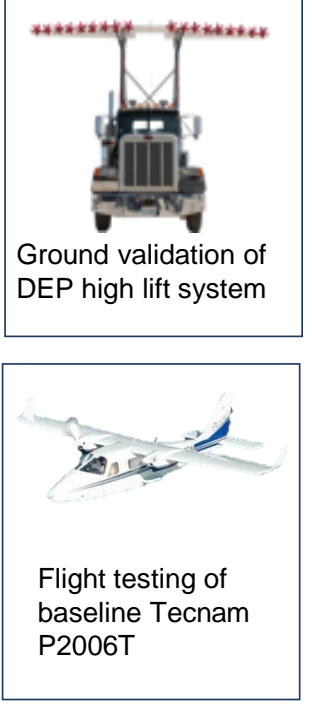

Goals:

Establish Baseline

Tecnam Performance

- Pilot Familiarity

Mod 1
Mod 3

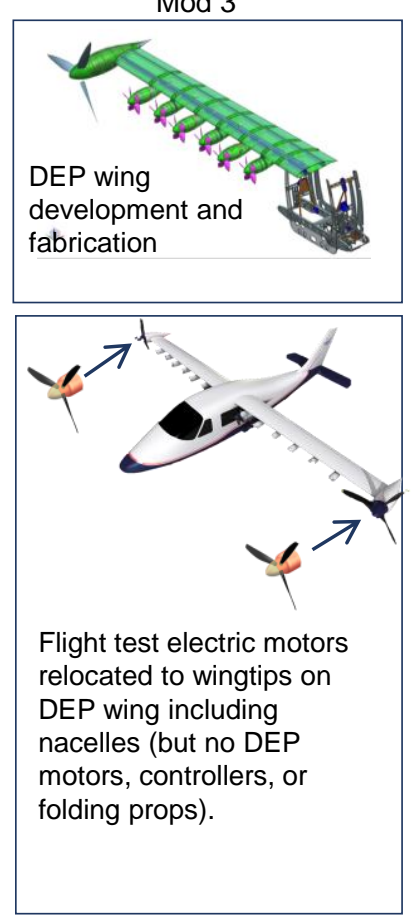

Achieves Primary Objective of

High Speed Cruise Efficiency
Spiral development

process

- Build - Fly - Learn

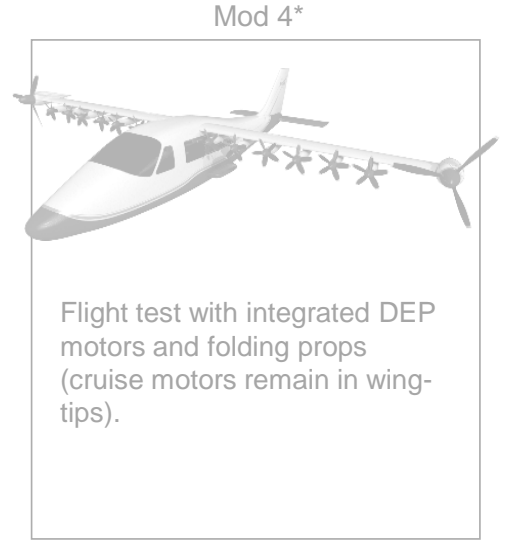

Achieves Secondary Objectives

- DEP Acoustics Testing

Low Speed Control Robustness

Certification Basis of DEP Technologies 


\section{Participating Organizations}

NASA Langley: Vehicle, Wing, Performance, Controls IPTs

NASA Armstrong: Power, Instrumentation IPTs, Flight Ops

NASA Glenn: Battery Testing, Thermal Analysis

Empirical Sys. Aero.: Prime contractor

Scaled Composites: Mod 2 Integration (batteries, motors, controllers, cockpit)

Joby Aviation: Motor \& Controller and folding prop development

Xperimental: Wing design and manufacturing

Electric Power Sys.: Battery development TMC Technologies: Software certification

Tecnam: Baseline COTS airframe without engines
TMC

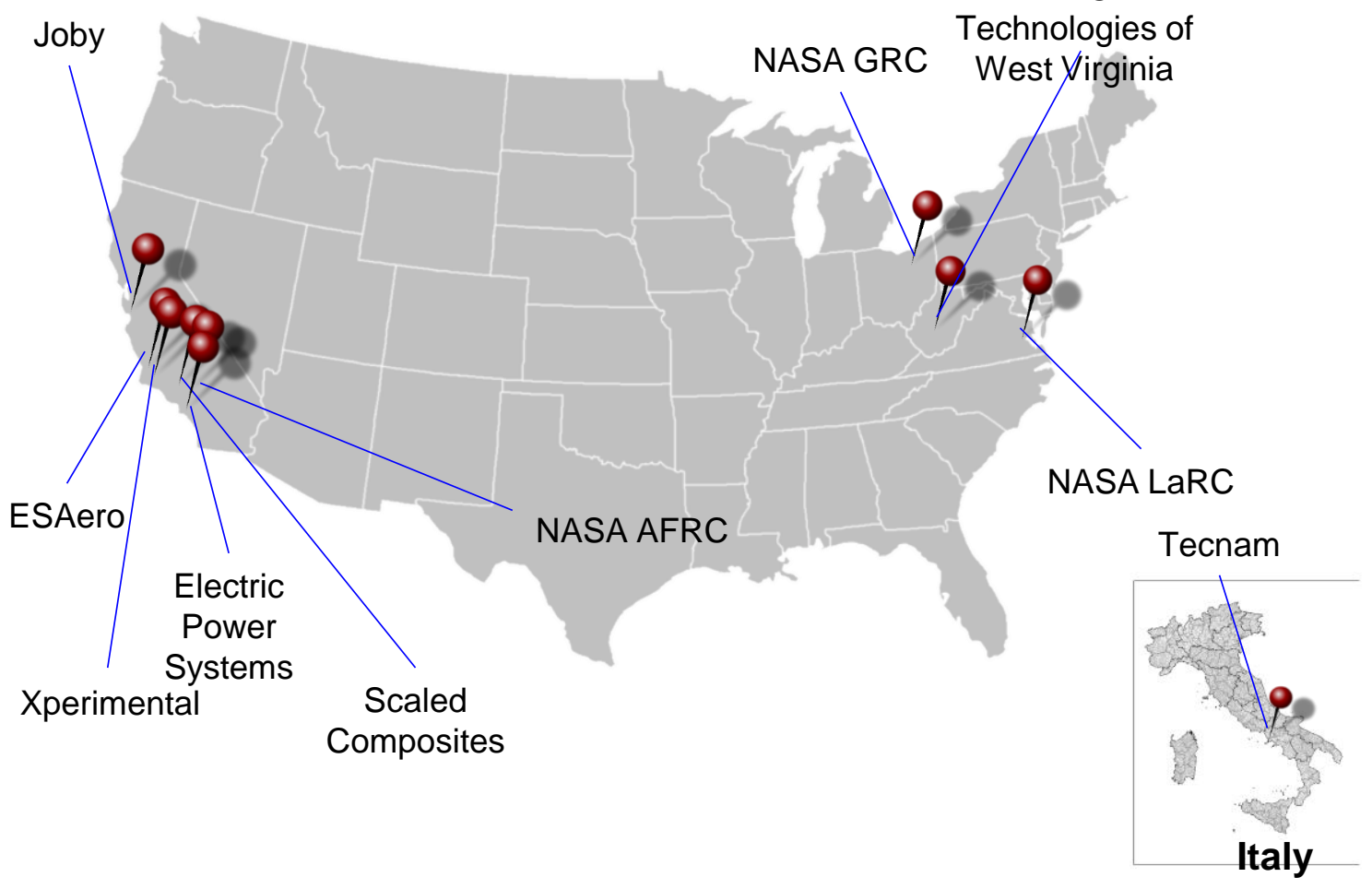




\section{New X-57 Fact Sheet}

\section{https://go.nasa.gov/2mMrPep}

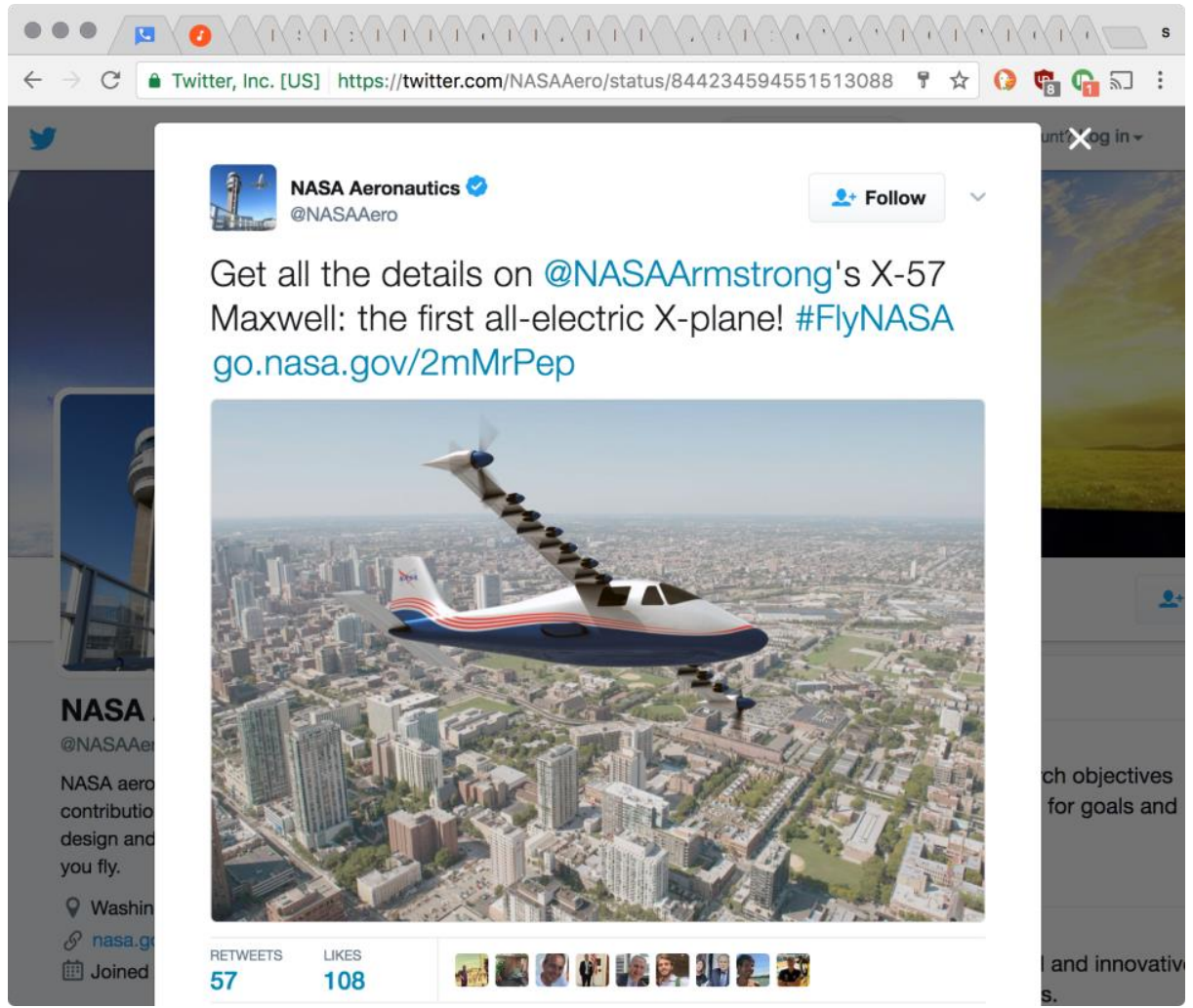




\section{Technical Progress}

\section{Mod III Wing Design}

- NASA and Xperimental finalizing design (CDR March 7-8)

- Current design considerations:

, Load Test Plan: Full-scale test article vs. sub-assembly tests

> Aileron \& flap resizing due to manufacturing concerns

, Analyses: Structural, classical flutter, whirl flutter analysis

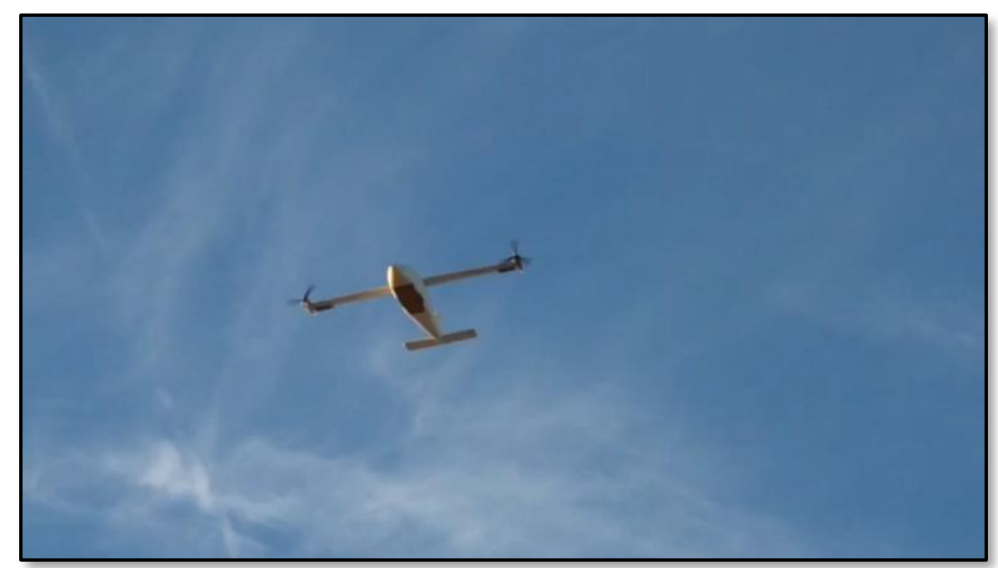

Remote Control Quick Look Stability \& Control Model
Aileron, Flap, High Lift Nacelle Interface (Nacelle's Empty in Mod III)
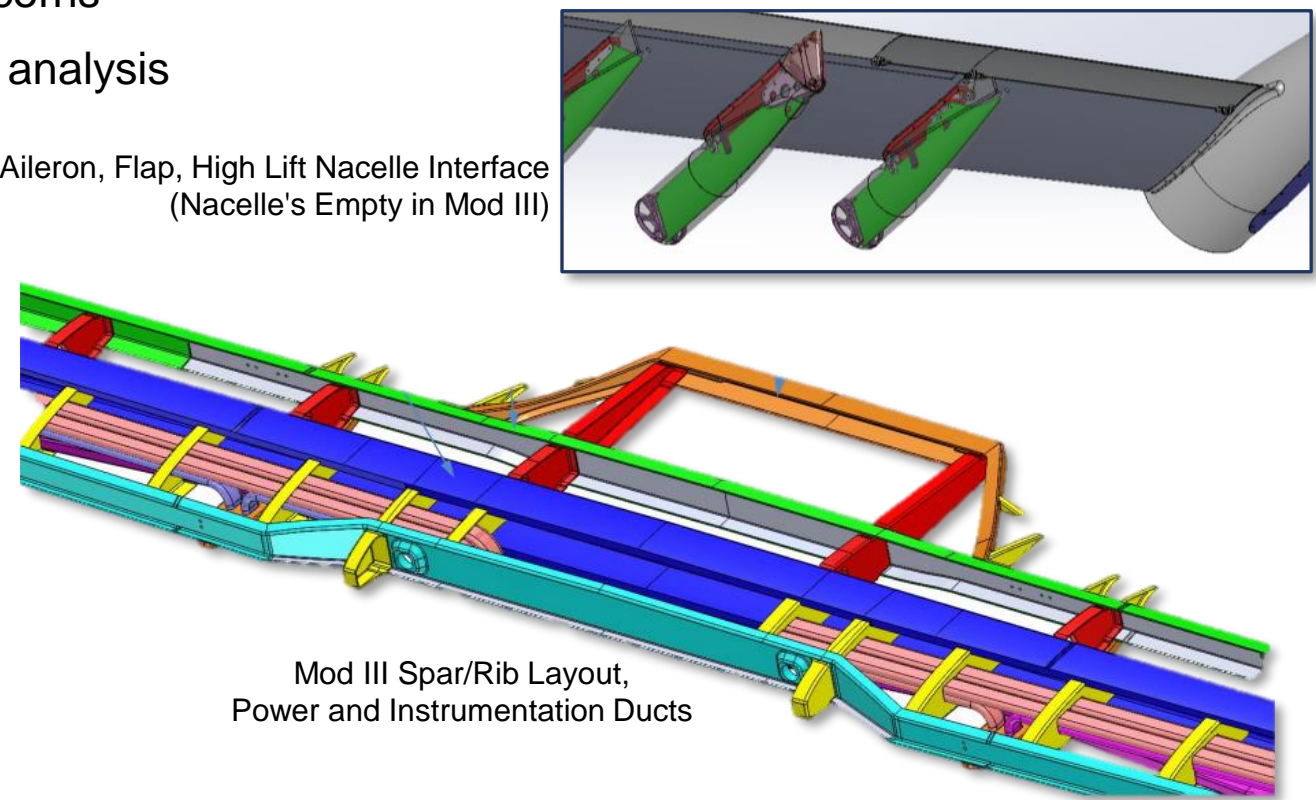


\section{Technical Progress}

\section{Traction Power Distribution}

Isolated Ducts Protect Redundant Power and Command for Cruise and DEP Systems
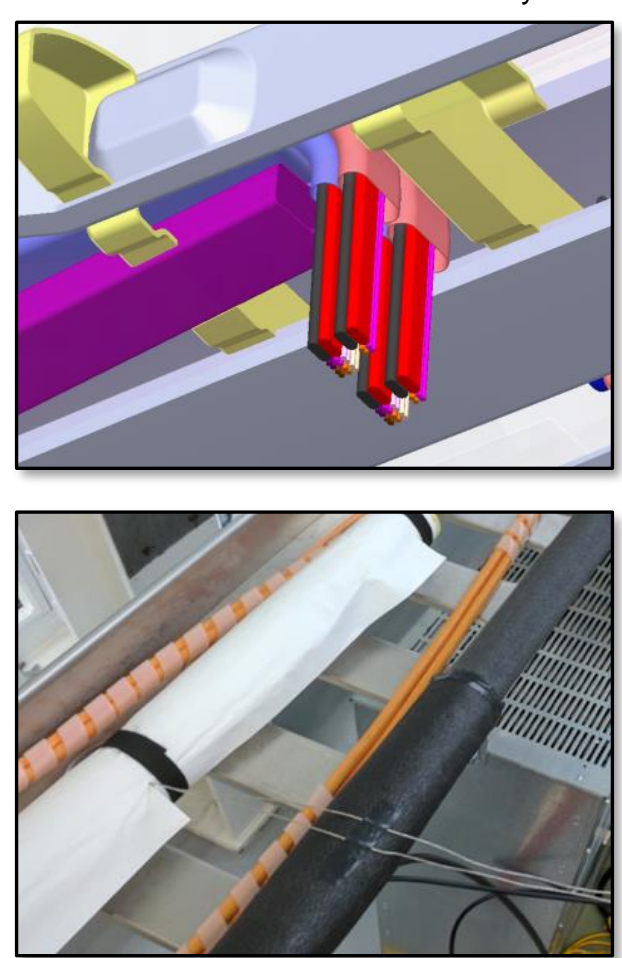

X-57 EMI Testing At Plum Brook Station/NEAT
Contactor Pallet Includes Smart Prechargers and "Primary Objective" Power Measurement
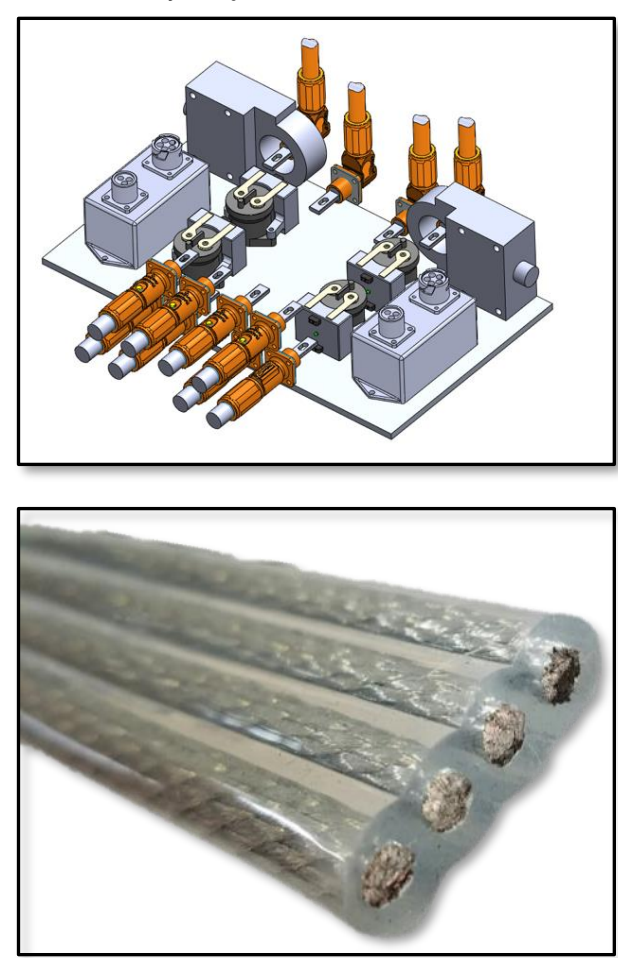

Flat Cable Custom X-57 Design for Electric Propulsion Systems 


\section{Internal Collaboration}

\section{With other NASA activities}

- NASA Electric Aircraft Testbed (NEAT) at GRC

, X-57 EMI Radiated Emissions test

, X-57 Traction Bus Thermal Model Validation

- X-57 Battery Characterization and Destructive Testing at GRC and JSC

- AirVolt Electric Propulsor Test Bed at AFRC (X-57 cruise motor acceptance and qualification)

- OpenMDAO system optimization toolkit (X-57 Thermal Models and X-57 Mission Profiling Tool)

- GRC Integrated Motor Controller (X-57 Mod IV DEP Motor Controllers)

- Hybrid Electric Integrated Systems Testbed (HEIST)

, Common electric aircraft facilities development (Hangar improvements for EP)

, X-57 Mod IV control-law development support

- Many TAC/CAS projects are using X-57 as a baseline configuration (FUELEAP and several others)

- NASA Flight Data Archival and Retrieval System (X-57 is the inaugural flight data set and is driving the initial requirements) 


\section{External Collaboration}

\section{New technologies $X-57$ is driving in industry}

- Automatic electric motor inverter precharge system (Electro.Aero, Australia)

- CAN Bus fiber optic bus modems (Western Reserve Controls, Ohio)

- Flat Traction Bus cable (Whitmore/Wirenetics, California)

- Large Li-lon Battery integration techniques (derived from JSC and GRC prior experience)

- Alternative high specific-power inverter design modeled on X-57 Mod IV DEP requirements (LaunchPoint, California) 